\title{
CARACTERIZAÇÃO FÍSICA DO BAGAÇO DE CANA-DEAÇÚCAR
}

\author{
C. V. L. CHAVES ${ }^{1}$, J. I. H. T. TAVARES NETO ${ }^{2}$ e S. H. V. CARVALHO ${ }^{3}$, J. I. SOLETTI ${ }^{3}$, A. P. \\ Ramos $^{1}$, S. B. B. L. Villar ${ }^{1}$ \\ ${ }^{1}$ Universidade Federal de Campina Grande, Departamento de Engenharia Química \\ ${ }^{2}$ Braskem S/A \\ ${ }^{3}$ Universidade Federal de Alagoas, Departamento de Engenharia Química \\ ${ }^{2}$ Braskem, \\ E-mail para contato: Viviane_chaves_@hotmail.com
}

\begin{abstract}
RESUMO - O bagaço de cana de açúcar tem sido bastante utilizado em pesquisas como biomassa para adsorção de substâncias orgânicas, pois possui características físicas, tais como porosidade, elevada área superficial e hidrofobicidade. Algumas das vantagens do uso do bagaço de cana no tratamento de efluentes são o baixo custo de aplicação e a facilidade de obtenção da biomassa em grande quantidade. Para confirmar a viabilidade do bagaço de cana como adsorvente é necessário realizar a caracterização física do mesmo. Para isso foi realizado um pré-tratamento para que possíveis contaminantes fossem evitados. O bagaço passou por uma seleção granulométrica, para obter partículas com tamanhos entre 0,4 e $2,36 \mathrm{~mm}$ e foram separadas amostras para os ensaios de caracterização física. Os experimentos realizados identificaram o teor de umidade, teor de cinzas sacarose e teor de material volátil. Os resultados apontam o bagaço de cana como um promissor bioadsorvente.
\end{abstract}

\section{INTRODUÇÃO}

A preocupação com a sustentabilidade e preservação do meio ambiente oriunda das atividades industriais tem incentivado pesquisas e desenvolvimento de tecnologias limpas, eficientes e de baixo custo operacional. Sendo assim, o estudo e aprimoramento de algumas técnicas de tratamento de efluentes é de grande importância para minimizar os impactos ambientais causados pela descarga de efluentes gerados pelas indústrias.

O processo de adsorção, por possuir características como ser de fácil implantação e operação, de baixo custo, e pela possibilidade de reutilizar os adsorventes (adsorção/dessorção), se apresenta como uma boa alternativa no tratamento de efluentes, para remoção de compostos orgânicos.

No processo de adsorção, além de adsorventes sintéticos, também são utilizados algumas biomassas para remoção de compostos orgânicos (os bioadsorventes), pois há biomassa com característica altamente hidrofóbica e de elevada porosidade, o que favorece seu uso na adsorção de óleos. Segundo Rubio (2003), tecidos vegetais, com alta área superficial e com grandes poros, adsorvem contaminantes orgânicos por mecanismos físico-químicos de uma maneira semelhante a do carvão ativado. 
Tsai et al. (2000) cita que os materiais como madeira, plantas aquáticas, resíduos industriais, entre outros, estão presentes em grande escala e podem ser utilizados como matéria prima para a fabricação de produtos adsorventes, como o carvão ativo, ou serem empregados, em sua forma "in natura" como materiais adsorventes, diminuindo o custo operacional do processo.

Dentre as principais vantagens no uso de biomassa estão o baixo custo, ser uma fonte renovável e transformar resíduos industriais em subprodutos da indústria.

Alvo de estudo em diversos trabalhos científicos, o bagaço de cana tem se mostrado um bom adsorvente para remoção de compostos orgânicos.

Brandão et al. (2010) estudaram a adsorção de hidrocarbonetos derivados do petróleo em solução aquosa com o bagaço de cana, obtendo bons resultados de adsorção; Santos em 2005, estudou a adsorção de contaminantes orgânicos oriundos de água de produção de petróleo utilizando biomassa como adsorvente, entre eles o bagaço de cana de açúcar; Peternele et al. (1999) estudaram a adsorção de $\mathrm{Cd}(\mathrm{II})$ e $\mathrm{Pb}$ (II) em lignina fórmica a partir de bagaço de cana. Todos esses estudos relatados acima mostraram um bom aproveitamento do bagaço de cana como adsorvente.

Esse trabalho visa estudar as características físicas do bagaço de cana para confirmar suas características como bioadsorvente.

\section{METODOLOGIA}

Os ensaios experimentais para caracterização da biomassa foram realizados na Universidade Federal de Alagoas (UFAL). Foi realizada a caracterização física do bagaço de cana em sua forma natural e com ativação ácida.

\subsection{Pré-tratamento e ativação ácida do bagaço de cana-de açúcar}

O bagaço foi cedido pela Usina Cachoeira, localizada em Maceió-AL.

Primeiramente,o bagaço foi exposto ao sol para retirar o excesso de umidade. Em seguida foi peneirado em peneiras da série Tyler para que houvesse a seleção de biomassa com granulometria entre $0,40 \mathrm{~mm}$ e $2,36 \mathrm{~mm}$. Após seleção granulométrica foi realizado um pré-tratamento da biomassa, consistindo em lavagem com água desmineralizada em abundância, para remoção de materiais como açúcares, taninos, lignina, entre outros, além da remoção de pedaços de palha, areia ou madeira, que podem interferir no processo de adsorção, e posterior secagem em estufa com temperatura de $70^{\circ} \mathrm{C}$.

Com a finalidade de avaliar se a ativação ácida do bagaço ofereceria melhorias no processo de adsorção, foram realizados experimentos para o bagaço nas duas condições:

1- Bagaço apenas lavado com água desmineralizada, seco em estufa a $70^{\circ} \mathrm{C}$ por 5 dias;

2- Bagaço lavado com água desmineralizada seguido por ativação ácida, conforme descrito a seguir, seco em estufa a $70^{\circ} \mathrm{C}$ por 5 dias. 
A Figura 1 ilustra as etapas da preparação do bagaço de cana para ativação ácida do bagaço, caracterização e utilização da biomassa nos experimentos.

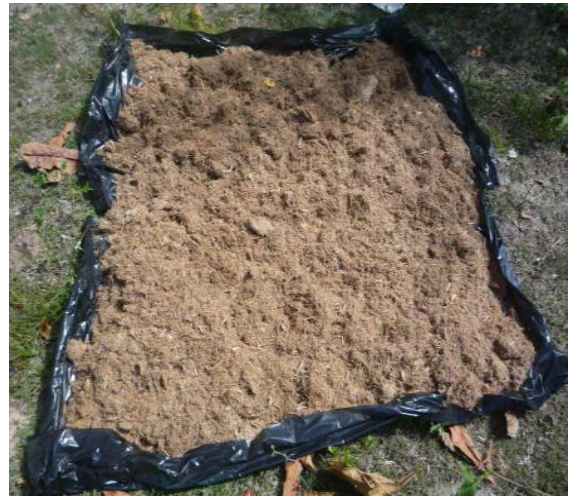

Secagem
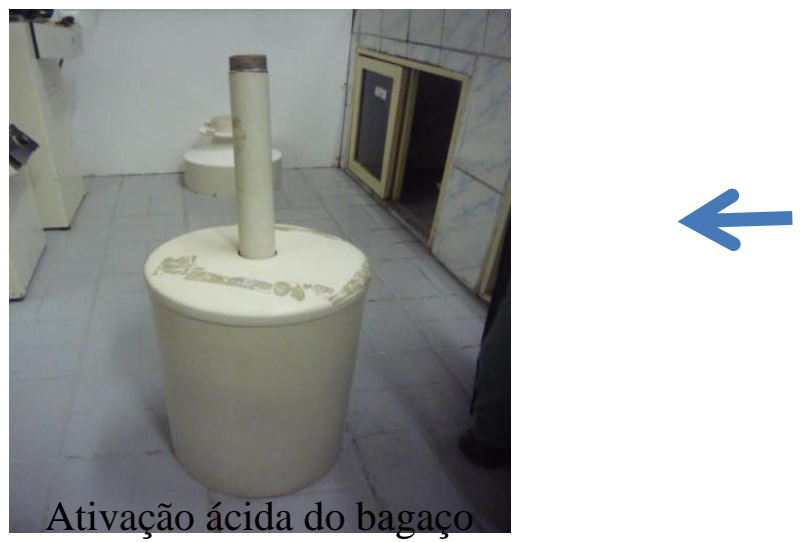

Figura 1 - Etapas da preparação do bagaço de cana para caracterização e utilização da biomassa nos experimentos

A ativação ácida do bagaço, após lavagem com água desmineralizada em abundância, foi obtida a partir de imersão do bagaço em solução de $\mathrm{HCl}, 2,0 \mathrm{M}$, em um tanque agitado por 30 minutos. $\mathrm{O}$ tratamento químico do bagaço teve como finalidade eliminar materiais que, possivelmente, estariam fixados na estrutura do material adsorvente, disponibilizando os sítios de adsorção.

Após o pré-tratamento e ativação ácida do bagaço o mesmo foi armazenado em sacos plásticos e guardado em local arejado até sua utilização nos experimentos.

\subsection{Caracterização física do bagaço de cana-de-açúcar}

Para caracterização do bagaço de cana-de-açúcar foram realizados os seguintes 
procedimentos:

Seleção Granulométrica; Determinação do teor de umidade; Determinação do teor de cinzas; Determinação do teor de matéria volátil;

\section{$\underline{\text { Seleção Granulométrica }}$}

A seleção granulométrica consiste em selecionar o bagaço com distribuição das partículas entre 0,4 e 2,36mm. Este ensaio foi realizado utilizando a série de peneiras TYLER em um vibrador. Para a seleção foram utilizadas as peneiras de malhas 8,20 e 40 e o bagaço selecionado foi o que ficou sobre as peneiras de malhas 20 e 40 .

\section{Determinação do Teor de Umidade}

O ensaio para determinação do teor de umidade tem como objetivo determinar a porcentagem de água presente na amostra do bagaço. A umidade corresponde ao peso da água na amostra do bagaço e é percebida pela perda de peso quando o bagaço é exposto a uma temperatura na qual a água é removida.

A Equação 1 expressa matematicamente como é possível obter o valor do teor de umidade (Tu):

$$
T_{U i}=\frac{M_{1}-M_{2}}{M_{1}} * 100
$$

Onde, M1é a massa do bagaço úmido (g); M2= Massa do bagaço seco (g).

Este procedimento foi realizado em estufa e seguiu o recomendado pela Associação Brasileira de Normas Técnicas (ABNT), NBR 8293.

Inicialmente foram pesadas em balança analítica 2 amostras de 1,00g de bagaço em cadinhos de porcelana previamente pesados. Em seguida, foram colocadas em estufa por 8 horas a temperatura de $105 \pm 5^{\circ} \mathrm{C}$. Depois de retirados da estufa, os cadinhos de porcelana foram colocados em dessecadores, para resfriar e em seguida foram novamente pesados.

\section{Determinação do Teor de Cinzas}

O teor de cinzas pode ser determinado por incineração simples. Silva (1990) descreve o procedimento com o aquecimento da amostra seca em mufla elétrica, com temperatura entre $500^{\circ} \mathrm{C}$ $(773 \mathrm{~K})$ e $600^{\circ} \mathrm{C}(873 \mathrm{~K})$, com tempo de permanência na estufa de quatro horas ou até a obtenção de cinza clara, a qual indica ausência de matéria orgânica.

O ensaio para a determinação do teor de cinzas de bagaço foi realizado a temperatura de $580^{\circ} \mathrm{C}$ (853K), por período de tempo de 4 horas. Para este procedimento seguiu-se a norma adotada pelo Instituto Adolfo Lutz (1985), o experimento foi realizado em duplicata. 
Inicialmente os cadinhos de porcelana foram colocados em mufla a uma temperatura de $100^{\circ} \mathrm{C}$ para retirada da umidade e em seguida foram pesados, tendo os pesos anotados. Estando ausente de umidade, foram acrescentados $2,0 \mathrm{~g}$ da amostra em cada cadinho e levados a mufla $\left(\mathrm{T}=580^{\circ} \mathrm{C}\right)$ por 4 horas. Passado esse tempo as amostras foram retiradas da mufla e colocadas em dessecador, para esfriar. Depois de esfriados os cadinhos foram pesados com a amostra seca. A Equação 2 possibilita calcular o teor de cinzas.

$$
\text { Teor de cinzas }=\frac{m_{2}}{m_{1}} * 100
$$

Onde mlé a massa da amostra inicial e m² é a massa da amostra após incineração.

A análise deste ensaio indica a riqueza da amostra em elementos minerais. O objetivo em fazer este experimento é conhecer o extrato não nitrogenado (ENN) e/ou a matéria orgânica. $O$ aquecimento vai provocar a decomposição dos compostos voláteis, eliminando-os e a matéria orgânica será transformada em CO2 e água.

\section{Determinação do Teor de Matéria Volátil}

O teor de matéria volátil foi determinado a partir procedimento encontrado na ABNT NBR 8290.

Inicialmente o cadinho de porcelana com tampa foi colocado em mufla a uma temperatura de $100^{\circ} \mathrm{C}$ para retirada da umidade e em seguida foi pesado, tendo o seu peso anotado. Estando este ausente de umidade, acrescentou-se 1,0g do bagaço, isento de umidade, sobre a porta da mufla previamente aquecida a $980^{\circ} \mathrm{C}$ por 3 minutos. Em seguida o cadinho é colocado no meio da mufla durante 7 minutos com a porta fechada. O cadinho então é retirado da mufla e colocado no dessecador para ser resfriado e, posteriormente, pesado. $\mathrm{O}$ teor de matéria volátil pode ser obtido pela Equação 3 e corresponde a quantidade de massa perdida em relação à massa inicial.

$$
\text { Teor de matéria volátil }=\frac{m_{1}-m_{2}}{m_{1}} * 100
$$

Onde m1 é a massa da amostra inicial e m2 é a massa da amostra calcinada.

\section{RESULTADOS E DISCUSSÃO}

\subsection{Caracterização física do bagaço de cana}

Antes de iniciar a caracterização física do bagaço, este passou por um pré-tratamento para que possíveis contaminantes fossem evitados. O bagaço passou por uma seleção granulométrica, para obter partículas com tamanhos entre 0,4 e 2,36mm e então foi utilizada a técnica de amostragem para obter as amostras que foram utilizadas nos ensaios para caracterização física do bagaço. 


\section{Determinação do Teor de Umidade}

Foram realizados dois ensaios experimentais para determinação do teor de umidade, os resultados são mostrados na Tabela 1 . O teor de umidade (\% umidade) foi determinado a partir da Equação 1.

Tabela 1 - obtidos no ensaio para determinação do teor de umidade do bagaço de cana

\begin{tabular}{ccccc}
\hline Experimentos & Amostra & $\begin{array}{c}\text { Peso amostra } \\
\text { inicial }(\mathrm{g})\end{array}$ & $\begin{array}{c}\text { Peso Amostra } \\
\text { final }(\mathrm{g})\end{array}$ & $\begin{array}{c}\% \text { Umidade } \\
\left(\mathrm{T}_{\mathrm{u}}\right)\end{array}$ \\
\hline 01 & Bagaço ácido & 0,330 & 0,320 & 2,850 \\
02 & Bagaço ácido & 0,390 & 0,380 & 3,050 \\
03 & Bagaço desmineralizado & 0,306 & 0,298 & 2,560 \\
04 & Bagaço desmineralizado & 0,307 & 0,297 & 3,320 \\
\hline
\end{tabular}

Pela média dos resultados das amostras 01 e 02 , para o bagaço ácido, tem-se o teor de umidade igual a 2,95 $\pm 0,14$ e para o bagaço desmineralizado, pela média dos resultados dos experimentos $03 \mathrm{e}$ 04 , o teor de umidade é igual a 2,950 $\pm 0,530$.

\section{Determinação do Teor de Cinzas}

$\mathrm{O}$ teor de cinzas foi determinado por incineração simples. O experimento foi realizado em duplicata e os resultados estão expressos na Tabela 2.

Tabela 2 - Resultados obtidos no ensaio para determinação do teor de cinzas do bagaço de cana

\begin{tabular}{ccccc}
\hline Experimentos & Amostra & $\begin{array}{c}\text { Peso amostra } \\
\text { inicial }(\mathrm{g})\end{array}$ & $\begin{array}{c}\text { Peso amostra } \\
\text { final }(\mathrm{g})\end{array}$ & $\begin{array}{c}\text { Teor de } \\
\text { cinzas }\left(\mathrm{T}_{\mathrm{c}}\right)\end{array}$ \\
\hline 01 & Bagaço ácido & 0,26 & 0,024 & 9,120 \\
02 & Bagaço ácido & 0,246 & 0,030 & 12,600 \\
03 & $\begin{array}{c}\text { Bagaço } \\
\text { desmineralizado }\end{array}$ & 0,261 & 0,008 & 3,064 \\
04 & $\begin{array}{c}\text { Bagaço } \\
\text { desmineralizado }\end{array}$ & 0,236 & 0,006 & 2,455 \\
\hline
\end{tabular}

O teor de cinzas de cada amostra foi calculado a partir da Equação 2.

Onde m1é a massa da amostra inicial e m2 é a massa da amostra após incineração. 
Pela média dos resultados das amostras 01 e 02, tem-se o teor de cinzas do bagaço de cana ácido igual a 10,90 $\pm 2,40$. Para o bagaço desmineralizado igual a 2,76 $\pm 0,43$.

\section{Determinação do Teor de Matéria Volátil}

O teor de matéria volátil foi determinado utilizando a Equação 33.

Tabela 3 - Resultados obtidos no ensaio para determinação do teor de matéria volátil do bagaço de cana

\begin{tabular}{ccccc}
\hline Experimento & Amostra & $\begin{array}{c}\text { Peso amostra } \\
\text { inicial }(\mathrm{g})\end{array}$ & $\begin{array}{c}\text { Peso Amostra } \\
\text { final }(\mathrm{g})\end{array}$ & $\begin{array}{c}\text { Teor de matéria volátil } \\
\left(\mathrm{T}_{\mathrm{MV}}\right)\end{array}$ \\
\hline 01 & Bagaço ácido & 0,320 & 0,008 & 97,4 \\
02 & Bagaço ácido & 0,380 & 0,015 & 96,0 \\
03 & $\begin{array}{c}\text { Bagaço } \\
\text { desmineralizado }\end{array}$ & 0,256 & 0,005 & 98,0 \\
04 & $\begin{array}{c}\text { Bagaço } \\
\text { desmineralizado }\end{array}$ & 0,224 & 0,012 & 94,5 \\
\hline
\end{tabular}

Pela média dos resultados das amostras 01 e 02 , tem-se o teor de matéria volátil do bagaço de cana ácido igual a 96,70 $\pm 1,00$ e para o bagaço desmineralizado o teor de matéria volátil é igual a $96,26 \pm 2,47$.

\section{CONCLUSÕES}

A partir dos resultados apresentados é possível concluir que:

Os resultados da caracterização do bagaço de cana mostram que a ativação ácida do bagaço provoca mudanças em suas características físicas e químicas, como o teor de cinzas, por exemplo, que

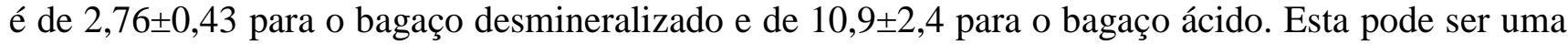
das razões para explicar a redução da capacidade adsortiva do bagaço, quando este é lavado com solução ácida.

\section{REFERÊNCIAS}

ASSOCIAÇÃO BRASILEIRA DE NORMAS TÉCNICAS. NBR 8290. Determinação do teor de materiais voláteis de carvão mineral, 1983.

ASSOCIAÇÃO BRASILEIRA DE NORMAS TÉCNICAS. NBR 8293. Determinação de umidade de carvão mineral, 1983. 
BRANDÃO, P. C.; SOUZA, T. C.; FERREIRA, C. A.; HORI, C. E.;ROMANIELO, L. I. Removal of petroleum hydrocarbons from aqueous solution using sugarcane bagasse as adsorbent. Journal of Hazardous Materials, v.175,p. 1106-1112, 2010.

LUTZ, I. A. Normas analíticas do instituto adolfo lutz. Métodos físico-químicos para análise de alimentos. 4. ed. 1. ed. digital, São Paulo, 2008. Disponível em: <http://www.ial.sp.gov.br/>. Acesso em: 7 out. 2012.

PETERNELE, W. S.; WINKLER-HECHENLEITNER, A. A.; PINEDA, E. A. G. Adsorption of $\mathrm{Cd}(\mathrm{II})$ and $\mathrm{Pb}(\mathrm{II})$ onto functionalized formic lignin from sugar cane bagasse. Bioresource Technology, v. 68, p. 95-100, 1999.

RUBIO, J. Pesquisa Gaúcha Desenvolve Adsorvente Natural de Óleos. 411. ed. Química e derivados online, 2003. Disponível em: http://www.quimica.com.br/atualidades>. Acesso em jan. 2012.

SANTOS, E. G.; ALSINA, O. L. S.; SILVA, F. L. H. Estudo da adsorção de contaminantes orgânicos provenientes da água de extração do petróleo, utilizando biomassas. 2005. $199 \mathrm{f}$. Tese (Doutorado em engenharia de processos) - Universidade Federal de Campina Grande, Paraíba, 2005.

TSAI, W. T.; CHANG, C. Y.; WANG, S. Y.; CHANG, C. F.; CHIEN, S. F.; SUN, H. F. Cleaner Production of Carbon Adsorbents by Utilization Agricultural Waste Corn Cob. Resources, Conservation and Recycling, v. 32, p. 43-53, 2000. 